\title{
Axicabtagene ciloleucel CD19 CAR-T cell therapy results in high rates of systemic and neurologic remissions in ten patients with refractory large B cell lymphoma including two with HIV and viral hepatitis
}

\author{
Ahmed Abbasi ${ }^{1+}$, Stephen Peeke ${ }^{1 \dagger}$, Nishi Shah ${ }^{1+}$, Jennat Mustafa ${ }^{1}$, Fariha Khatun ${ }^{1}$, Amanda Lombardo ${ }^{1}$, \\ Michelly Abreu', Richard Elkind ${ }^{1}$, Karen Fehn ${ }^{1}$, Alyssa de Castro², Yanhua Wang ${ }^{3}$, Olga Derman', Randin Nelson ${ }^{3}$,

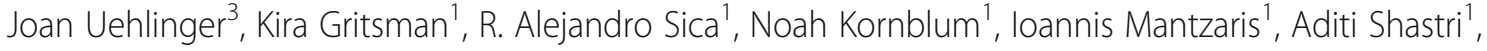 \\ Murali Janakiram', Mendel Goldfinger ${ }^{1}$, Amit Verma', Ira Braunschweig ${ }^{1}$ and Lizamarie Bachier-Rodriguez ${ }^{1 *}$
}

\begin{abstract}
Axicabtagene ciloleucel (Axi-cel) is a CD-19 Chimeric Antigen Receptor T cell therapy approved for the treatment of relapsed/refractory diffuse large B cell lymphoma. We treated ten patients with DLBCL post-FDA approval in an inner-city tertiary center in the Bronx. Eight patients (80\%) had received $\geq 3$ lines of therapy, six patients had received prior radiation, and seven had recurrent disease after prior autologous hematopoietic stem cell transplant (AHCT). Our cohort included one patient with HIV, two patients with hepatitis B, and two patients with CNS involvement of lymphoma. Axi-cel treatment led to significant responses with 8/10 patients achieving a complete remission at 3 months, including both patients with prior CNS involvement. The treatment was generally well tolerated with $20 \%$ of patients experiencing grade $\geq 2 \mathrm{CRS}$. One patient each with HIV and hepatitis B responded without significant toxicities. In conclusion, Axi-cel led to significant efficacy with manageable toxicity in DLBCL in a real-world setting.
\end{abstract}

Keywords: CD19 CAR-T, HIV and CD-19 CAR-T, CNS and CD-19 CAR-T, Axi-cel, Hepatitis B and CD-19 CAR-T

To the Editor,

CD-19 Chimeric Antigen Receptor-T (CAR-T) cell therapy is FDA approved for the treatment of refractory or recurrent $(\mathrm{R} / \mathrm{R})$ diffuse large $\mathrm{B}$ cell lymphoma (DLBCL). The two commercially available cellular products, axicabtagene ciloleucel [Axi-cel] and Tisagenlecleucel have shown complete response in 54\% of 111 and $40 \%$ of 93 patients, respectively, in clinical trials [1-4]. The most concerning side effects are cytokine release syndrome (CRS) and immune effector cell-associated neurotoxicity syndrome (ICANS) [4-6]. We evaluated efficacy

\footnotetext{
*Correspondence: Ibachier@montefiore.org

${ }^{\dagger}$ Ahmed Abbasi, Stephen Peeke and Nishi Shah contributed equally to this work.

${ }^{1}$ Department of Oncology, Montefiore Medical Center, Albert Einstein College of Medicine, The Bronx, NY, USA

Full list of author information is available at the end of the article
}

and safety of Axi-cel post-FDA approval in an inner-city tertiary medical center.

We retrospectively reviewed the first ten $\mathrm{R} / \mathrm{R}$ DLBCL patients that were treated with Axi-cel between June 2018 and June 2019 at our center. We collected laboratory and clinical parameters and responses post-CAR-T by $\mathrm{PET} / \mathrm{CT}$. All patients received lymphodepleting chemotherapy per product guidelines with fludarabine and cyclophosphamide [2].

Patient disease characteristics including high-risk features (rearrangements or expression of BCL-2, MYC, BCL-6) and treatment characteristics are summarized in Table 1. Four patients had non-GCB DLBCL and four had transformed from prior low-grade disease (three follicular lymphomas and one lymphoplasmacytic lymphoma). Six patients had received prior radiation, and 
Table 1 Patient and treatment characteristics

\begin{tabular}{|c|c|}
\hline \multirow[t]{2}{*}{ Patient characteristics } & $N=10$ \\
\hline & $n(\%)$ \\
\hline Median age (range) years & $66(55-77)$ \\
\hline Female gender & $5(50 \%)$ \\
\hline ECOG performance status $\geq 2$ & $2(20 \%)$ \\
\hline \multicolumn{2}{|l|}{ Ethnicity } \\
\hline Hispanics & $4(40 \%)$ \\
\hline White & $3(30 \%)$ \\
\hline African American & $2(20 \%)$ \\
\hline Asian & $1(10 \%)$ \\
\hline Disease characteristics & $n(\%)$ \\
\hline Non-GCB DLBCL & $4(40 \%)$ \\
\hline Transformed lymphoma & $3(30 \%)$ \\
\hline Double expressor lymphoma & $6(60 \%)$ \\
\hline Triple expressor lymphoma & $2(20 \%)$ \\
\hline Double hit lymphoma & $1(10 \%)$ \\
\hline Triple hit lymphoma & $1(10 \%)$ \\
\hline P53 deletion by FISH & $1(10 \%)$ \\
\hline \multicolumn{2}{|l|}{ Disease stage } \\
\hline Stage I & 0 \\
\hline Stage II & $1(10 \%)$ \\
\hline Stage III & $4(40 \%)$ \\
\hline Stage IV & $5(50 \%)$ \\
\hline \multicolumn{2}{|l|}{ Number of prior lines of therapy } \\
\hline 1 & 0 \\
\hline 2 & $2(20 \%)$ \\
\hline 3 & $3(30 \%)$ \\
\hline 4 & $5(50 \%)$ \\
\hline CNS involvement & $2(20 \%)$ \\
\hline Prior AHCT & $7(70 \%)$ \\
\hline Response to treatment & $n(\%)$ \\
\hline CR at 3 months & $8(80 \%)$ \\
\hline POD & $1(10 \%)$ \\
\hline \multicolumn{2}{|l|}{ Adverse events } \\
\hline CRS & $6(60 \%)$ \\
\hline CRS grade $\geq 2$ & $2(20 \%)$ \\
\hline ICANS & $5(50 \%)$ \\
\hline ICANS grade $\geq 2$ & $3(30 \%)$ \\
\hline Tocilizumab & $3(30 \%)$ \\
\hline Glucocorticoids & $1(10 \%)$ \\
\hline Neutropenia $(<500 \mathrm{c} / \mu \mathrm{l})$ & $10(100 \%)$ \\
\hline Neutropenic fever & $8(80 \%)$ \\
\hline Thrombocytopenia $(<50,000 \mathrm{c} / \mu \mathrm{l})$ & $7(70 \%)$ \\
\hline Documented infection & $5(50 \%)$ \\
\hline
\end{tabular}

seven had prior autologous stem cell transplant. Two patients had prior CNS involvement. One had received intrathecal (IT) methotrexate 3 months prior to CAR-T. The other patient had a history of leptomeningeal disease and sixth cranial nerve palsy previously treated with high-dose methotrexate and IT chemotherapy. The latter patient had disease recurrence in the left nasopharynx prior to CAR-T infusion. Two patients had active HBV infection and were on anti-viral treatment. One patient had HIV and was on anti-retroviral therapy with undetectable viral load prior to therapy with CD4 count of 127 cells $/ \mu \mathrm{l}$.

Post-CAR-T, patients had a peak in temperature at day 5. All patients developed neutropenia (absolute neutrophil count $(\mathrm{ANC})$ of $<500 \mathrm{c} / \mu \mathrm{l})$ with duration of $\sim 6$ days and ANC nadir occurred on day 6 post-infusion. Neutropenic fever occurred in $8 / 10$ patients. Platelet count nadir and maximum CRP elevation also occurred at around day 6. Lymphocyte depletion was achieved in all patients prior to CAR-T. Lymphopenia lasted 2 weeks, with lymphocyte recovery seen at day 12 . Mean length of hospital stay was 22.8 days.

CRS and ICANS were evaluated and graded per ASTCT guidelines [7]. CRS was seen in six patients $(\geq$ grade 2 CRS in two). ICANS was observed in five patients ( $\geq$ grade 3 ICANS in three). Three patients received tocilizumab. Two patients developed Clostridium difficile colitis, one of whom required a MICU stay for hypotension with requirement of one pressor for $<48 \mathrm{~h}$ (grade 3 CRS) and eventually had full recovery.

Figure 1 shows responses and follow-up for all treated patients (data cutoff October 15, 2019). Eight of 10 patients achieved a CR including the two patients with prior CNS involvement, HIV patient, and one patient with $\mathrm{HBV}$, as assessed by PET/CT (Fig. 2). Additional file 1: Table S1 shows viral load information on HIV and HBV patients.

One patient had clear progression of disease (PD) within a month of treatment and died 4 months later due to complications of his disease. His lymphoma had transformed from prior low-grade disease and had acquired a TP53 deletion. He was positive for hepatitis B core Ab.

One patient developed severe neurotoxicity, requiring tocilizumab and glucocorticoids, and expired during hospital stay. This patient had an aggressive, triple expressor lymphoma (BCL-2, BCL-6, and MYC) with widespread extra-nodal disease but no prior CNS involvement. Brain imaging prior to death showed vasogenic edema and mass effect suspicious for mass, but given the patient's altered mental status, a high-quality diagnostic study was not obtained. CSF cytology was negative for malignant cells. Another patient who developed grade 1 ICANS post-CAR-T had a CR on PET/CT 

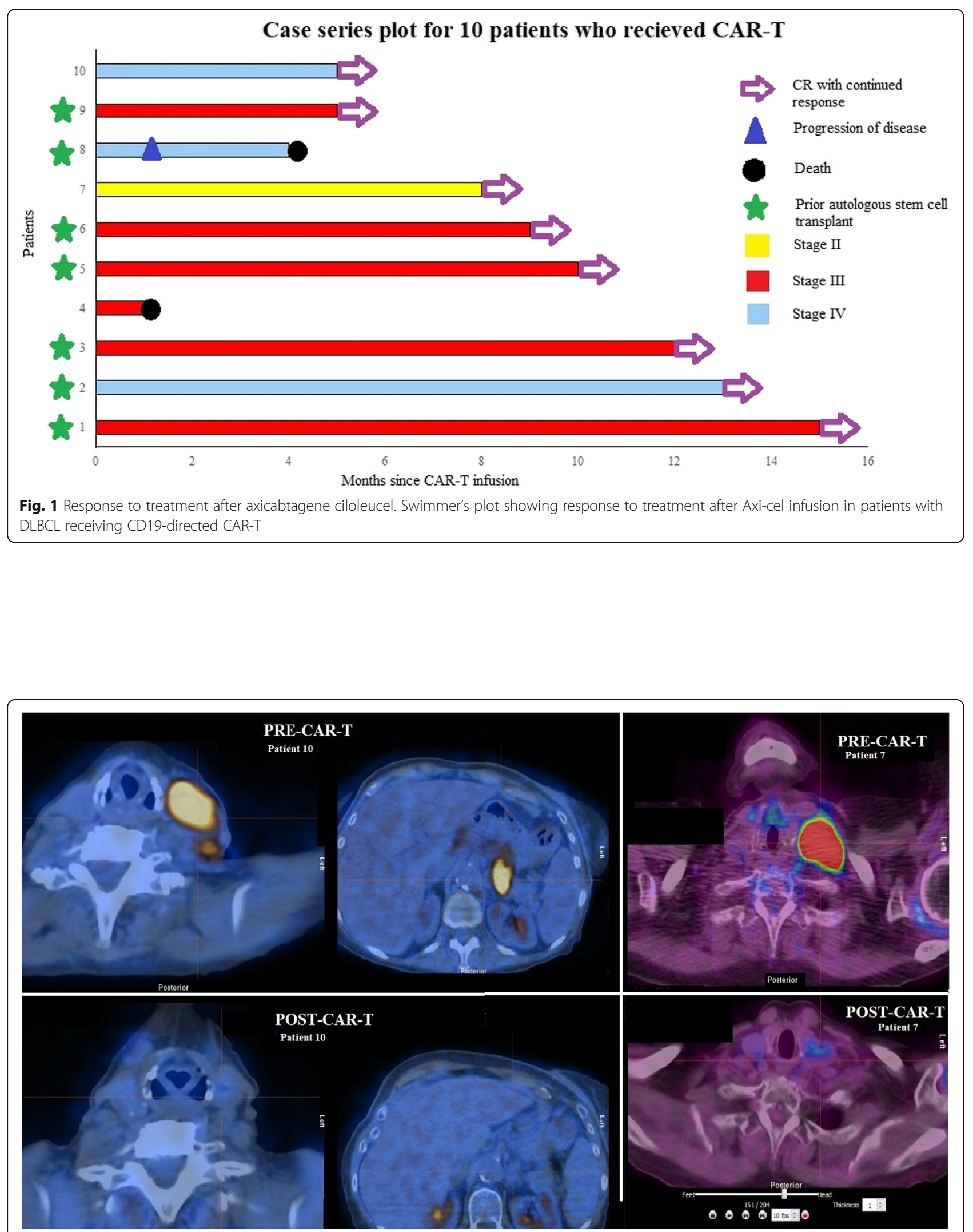

Fig. 2 PET-CT images of patients treated with axicabtagene ciloleucel. Pre-CAR-T (above) ad post-CAR-T (below) images show improvement in left cervical and left paraaortic lymphadenopathy in patient 10 and improvement in left cervical lymphadenopathy in patient 7 
but remains with significant cognition issues posttreatment at last follow-up.

Our data supports the feasibility of delivering CAR-T to heavily pre-treated patients within a reasonable time frame: 1 month from collection to infusion and 2-3 weeks of hospitalization during treatment. Our series show severe episodes occurred in $<25 \%$ of patients which is lower than previously reported.

It is encouraging to see the high rate of CR in heavily pretreated patients in a real-world setting especially for those with CNS involvement, HIV, and active HBV as these patients were excluded from the original clinical trial. The two deaths seen in our cohort were related to lymphoma progression (one confirmed on PET/CT and another patient who had CNS imaging concerning for mass effect vs. vasogenic edema post-CAR-T). The potential for longer-term adverse effects, as seen in the cognitive issues post-treatment for one patient, warrants continued monitoring.

In conclusion, our study adds to the mounting evidence of the safety and efficacy of CD-19-directed CAR$T$ therapy in aggressive DLBCL patients with severe comorbidities (CNS involvement, HIV, HBV) in a realworld setting [8-10].

\section{Supplementary information}

Supplementary information accompanies this paper at https://doi.org/10. 1186/s13045-019-0838-y.

Additional file 1: Table S1. Viral load and other lab parameters for

three patients (1 HIV, 2 patients with HBV).

\section{Abbreviations}

AHCT: Autologous hematopoietic stem cell transplant; ALL: Acute lymphoblastic leukemia; ANC: Absolute neutrophil count; ART: Anti-retroviral therapy; CAR-T: CD-19 Chimeric Antigen Receptor-T; CR: Complete response; CRS: Cytokine release syndrome; DEL: Double expressor lymphoma; DLBCL: Diffuse large B cell lymphoma; ICANS: Immune effector cellassociated neurotoxicity syndrome; IHC: Immunohistochemistry; IT: Intrathecal; TEL: Triple expressor lymphoma

\section{Acknowledgements}

Not applicable.

\section{Authors' contributions}

AA, SP, and NS collected the data, analyzed it, and wrote the first draft of manuscript. JM, FK, AL, MA, and RE took care of these patients and assisted in collecting data. $K F, A C$, and $Y W$ provided input in figures and table. $O D$, $K G, R S, N K, I M, A S$, and $M G$ contributed to the manuscript. $A V$, IB, and $L B$ wrote the final draft of manuscript. All authors read and approved the final manuscript.

\section{Funding}

None

\section{Availability of data and materials}

All data generated or analyzed during this study are included in this published article.

\section{Ethics approval and consent to participate}

This is an observational study; hence, no ethics approval and consent to participate required.
Consent for publication

Images are unidentifiable; hence, no consent is obtained.

\section{Competing interests}

The authors declare they have no competing interest.

\section{Author details}

'Department of Oncology, Montefiore Medical Center, Albert Einstein College of Medicine, The Bronx, NY, USA. 'Department of Pharmacy,

Montefiore Medical Center, The Bronx, NY, USA. ${ }^{3}$ Department of Pathology, Montefiore Medical Center, The Bronx, NY, USA.

Received: 26 October 2019 Accepted: 17 December 2019 Published online: 03 January 2020

\section{References}

1. Maude SL, Laetsch TW, Buechner J, Rives S, Boyer M, Bittencourt H, et al. Tisagenlecleucel in children and young adults with B-cell lymphoblastic leukemia. N Engl J Med. 2018;378(5):439-48.

2. Neelapu SS, Locke FL, Bartlett NL, Lekakis LJ, Miklos DB, Jacobson CA, et al. Axicabtagene ciloleucel CAR T-cell therapy in refractory large B-cell lymphoma. N Engl J Med. 2017:377(26):2531-44.

3. Schuster SJ, Bishop MR, Tam CS, Waller EK, Borchmann P, McGuirk JP, et al. Tisagenlecleucel in adult relapsed or refractory diffuse large B-cell lymphoma. N Engl J Med. 2018;380(1):45-56.

4. Locke FL, Ghobadi A, Jacobson CA, Miklos DB, Lekakis L, Oluwole OO, et al. Long-term safety and activity of axicabtagene ciloleucel in refractory large B-cell lymphoma (ZUMA-1): a single-arm, multicentre, phase 1-2 trial. Lancet Oncol. 2019;20(1):31-42.

5. Wang Z, Han W. Biomarkers of cytokine release syndrome and neurotoxicity related to CAR-T cell therapy. Biomark Res. 2018;6:4.

6. Porter D, Frey N, Wood PA, Weng Y, Grupp SA. Grading of cytokine release syndrome associated with the CAR T cell therapy tisagenlecleucel. J Hematol Oncol. 2018;11(1):35.

7. Lee DW, Santomasso BD, Locke FL, Ghobadi A, Turtle CJ, Brudno JN, et al. ASTCT consensus grading for cytokine release syndrome and neurologic toxicity associated with immune effector cells. Biology of Blood and Marrow Transplantation. 2019;25(4):625-38.

8. Nastoupil LJ, Jain MD, Spiegel JY, Ghobadi A, Lin Y, Dahiya S, et al. Axicabtagene ciloleucel (Axi-cel) CD19 chimeric antigen receptor (CAR) Tcell therapy for relapsed/refractory large B-cell lymphoma: real world experience. Blood. 2018;132(Supplement 1):91.

9. Frigault MJ, Dietrich J, Martinez-Lage M, Leick M, Choi BD, DeFilipp Z, et al. Tisagenlecleucel CAR T-cell therapy in secondary CNS lymphoma. Blood. 2019;134(11):860-6.

10. Abramson JS, Irwin KE, Frigault MJ, Dietrich J. McGree B, Jordan JT, et al. Successful anti-CD19 CAR T-cell therapy in HIV-infected patients with refractory high-grade B-cell lymphoma. Cancer. 2019;125(21):3692-8. https:// doi.org/10.1002/cncr.32411. Epub 2019 Sept 10.

\section{Publisher's Note}

Springer Nature remains neutral with regard to jurisdictional claims in published maps and institutional affiliations.

Ready to submit your research? Choose BMC and benefit from:

- fast, convenient online submission

- thorough peer review by experienced researchers in your field

- rapid publication on acceptance

- support for research data, including large and complex data types

- gold Open Access which fosters wider collaboration and increased citations

- maximum visibility for your research: over $100 \mathrm{M}$ website views per year

At BMC, research is always in progress.

Learn more biomedcentral.com/submissions 